\title{
ERRATUM
}

\section{Proximal amputation of inferior extremity secondary to recurrent pressure ulcers in patients with spinal cord injuries}

GI Correa, WO Calderón, RG Roa, LM Guzmán, LA Burnier and SE Danilla

Spinal Cord (2008) 46, 530; doi:10.1038/sj.sc.3102118

Correction to: Spinal Cord advance online publication, 3 July 2007; doi:10.1038/sj.sc.3102089

Since the publication of the above article, the authors have noticed that the ordering of the author names was incorrect.
The correct ordering of the author names is shown below.

GI Correa, WO Calderón, LA Burnier, SE Danilla, RG Roa and LM Guzmán

The typesetters would like to apologize for this mistake. 